\title{
Effective development of innovative technologies as a method for increasing labor productivity in industry
}

\author{
Andrei Dragunov ${ }^{1, *}$, and Yuri Shenshinov ${ }^{2}$ \\ ${ }^{1}$ Inha University, Incheon, South Korea \\ ${ }^{2}$ Ural State University of Economics, 8 Marta / Narodnoy Street 62/45, 620144 Yekaterinburg, \\ Russian Federation
}

\begin{abstract}
This article is devoted to the study of issues of increasing the efficiency and productivity of labor in industrial enterprises in the context of the use of innovation. We have proven a direct relationship between innovation and labor productivity. The main postulate is made in the article that the more invested in innovative technologies, the higher labor productivity. Moreover, a new indicator has been introduced - the innovative activity of personnel, which shows the share of human resources employed in innovative processes.
\end{abstract}

\section{Introduction}

In modern conditions of functioning of the economy, innovation is certainly a key factor in its development. Today, it is no secret that those countries where the policy and strategy of innovation are implemented have a huge advantage in world markets. A striking example is China, which is currently building a "Silicon Valley" on its territory. According to the country's leadership, the innovative path will lead China to higher positions and strengthen its authority on the world stage. We are witnessing how the use of high technologies dictates certain prospects for individual companies and firms, especially in industry. Therefore, innovation can be considered as a tool for the development of a manufacturing company and the state as a whole.

However, the innovative approach to economic activity is not limited to production strategies. Modern approaches to innovation management can also involve the development of finance, accounting, operational management, and human resources. The philosophy of any company cannot ignore the human factor. At all times, human resource management has been the most critical issue for company management. This is due to the fact that labor is a combination of physical and mental efforts of an individual to create a product or service. Therefore, work depends on many factors, including the psychological state of employees. If it is possible to manage finances or material reserves solely in accordance

\footnotetext{
* Corresponding authors: $\underline{\text { shenshinov@gmail.com }}$
} 
with economic laws, then human resource management is based on the concept of a person as an individual, his labor potential.

We need to understand whether there is a connection between innovation and work. In other words, how do innovative technologies affect the efficiency of work? In this regard, it is advisable to consider the relationship between innovative technologies and labor productivity. Labor productivity, as you know, is the main indicator of the result of labor activity in the company. Therefore, we will use this indicator as a "litmus test" to identify deviations in the process of implementing innovations in a production company.

As you know, human labor is actively used in the implementation of innovative technologies. On the one hand, people develop projects that will be implemented in the future, and on the other hand, people produce these goods and provide services for their further operation. It is difficult to underestimate the human factor in the implementation of innovative technologies. Nowadays, absolutely any production enterprise that uses even the maximum degree of the technological structure increases the importance of labor resources. In lean manufacturing, the focus is also on the human factor, since the optimization of operational processes is carried out exclusively by the skills of people.

Moreover, innovative technologies are currently being actively used in working with personnel. There are many approaches to optimizing the workforce and improving the efficiency of their work. Modern society has developed several important theories to describe the interest of personnel in using innovative technologies in industrial companies, which makes it possible to increase labor productivity.

\section{Materials and methods}

At the first stage, we will carry out a correlation analysis using the OLS (Ordinary Least Square) method and establish a correlation between the innovative activity of industrial production organizations and the dynamics of labor productivity (table 1).

Table 1. Innovative activity of industrial production organizations (the share of industrial production organizations implementing technological, organizational and (or) marketing innovations) and labor productivity dynamics (growth rate as a percentage of the previous year)

\begin{tabular}{|c|c|c|}
\hline Year & Innovative activity of organizations & Dynamics of labor productivity $(\%)$ \\
\hline 2010 & 10.8 & 3.2 \\
\hline 2011 & 11.1 & 3.8 \\
\hline 2012 & 11.1 & 3.3 \\
\hline 2013 & 10.9 & 2.2 \\
\hline 2014 & 10.9 & 0.7 \\
\hline 2015 & 10.6 & -1.9 \\
\hline 2016 & 10.5 & -0.3 \\
\hline 2017 & 10.6 & 1.5 \\
\hline
\end{tabular}

To calculate the correlation coefficient $r$, we use the formula 1 ,

$$
r=\frac{\sum\left(x_{i}-\bar{x}\right) \cdot\left(y_{i}-\bar{y}\right)}{\sqrt{\sum\left(x_{i}-\bar{x}\right)^{2}} \cdot \sqrt{\sum\left(y_{i}-\bar{y}\right)^{2}}}
$$

where we take the innovative activity of enterprises for $\mathrm{x}$, and the dynamics of labor productivity for $y$. 
For the given set of empirical data, the correlation coefficient turned out to be 0.767 . We calculate the test statistics $\xi$ using formula 2 and compare it with the tabular value of the Student coefficient $f(p=0.95, f=\infty)=1.96$

$$
\xi=\left(0.5 \cdot \ln \left(\frac{1+r}{1-r}\right)-\frac{|r|}{(2(n-1)}\right) \sqrt{n-3}
$$

where $\mathrm{n}$ is the number of dimensions.

As a result of calculations, the value of $\xi$ is equal to 2.142 from which it can be concluded that there is a strong correlation between the innovative activity of industrial enterprises and the dynamics of labor productivity of industrial enterprises.

To estimate the parameters of paired linear regression of the presented values, we use the least squares method (OLS) as one of the most important methods of regression analysis of empirical data. In other words, we find a function that most closely approximates the relationship of the variables $\mathrm{x}$ and $\mathrm{y}$. So, it is necessary to find the function $f(x, b)$ up to some parameters $\mathrm{b}$, which approximate the values of $f(x, b)$ to the actual values of $y$.

The equation for the dependence of the indicator of the dynamics of labor productivity (y) on the innovative activity of enterprises $(x)$ in paired linear regression has the form:

$$
y_{i}=\alpha+\beta x_{i}+\varepsilon_{i}
$$

where $\varepsilon_{i}$ - are the so-called random model errors. (4).

It is necessary to find a value of $\beta$ at which the sum of squared errors $\varepsilon_{i}$ will be minimal

$$
\min \sum\left(y_{i}-\beta x_{i}-\alpha\right)^{2}
$$

The sum of the squared errors will be minimal when $\frac{d f}{d \alpha}=0$ and $\frac{d f}{d \beta}=0$.

We write the derivatives in the form (5) and (6).

$$
\begin{aligned}
& \frac{d f}{d \alpha}=-2 \sum\left(y_{i}-\beta x_{i}-\alpha\right) \\
& \frac{d f}{d \beta}=2 \sum\left(y_{i}-\beta x_{i}-\alpha\right) x_{i}
\end{aligned}
$$

Having solved the resulting system of equations (5) and (6), it is easy to find estimates of the coefficients:

$$
\begin{aligned}
& \beta=\frac{n \sum x_{i} y_{i}-\sum x_{i} \sum y_{i}}{n \sum x_{i}^{2}-\left(x_{i}\right)^{2}} \\
& \alpha=\frac{\sum y_{i}-\beta \sum x_{i} \sum y_{i}}{n}
\end{aligned}
$$

As the main indicator reflecting the quality of the obtained coefficients and the 
regression model as a whole, we will use the determination coefficient, which shows the proportion of variation of the explained variable, taken into account in the model and due to the influence of factors included in the model on it. The coefficient of determination is calculated using formula (9).

$$
R^{2}=1-\frac{\sum\left(y_{i}-\hat{y}_{i}\right)^{2}}{\sum\left(y_{i}-\bar{y}_{i}\right)^{2}}
$$

where $\hat{y}_{i}-$ are the model values of the dynamics of labor productivity, and $\bar{y}_{i}-$ is the average value for the period under consideration.

The calculation results are presented in table 2.

Table 2. The values of the parameters of the resulting model

\begin{tabular}{|c|c|c|}
\hline $\boldsymbol{\alpha}$ & $\boldsymbol{\beta}$ & $\mathbf{R}^{\mathbf{2}}$ \\
\hline-69.8 & 6.6 & 0.587975292 \\
\hline
\end{tabular}

Thus, we can say that our least squares model reflects $59 \%$ of the variation of the dependent quantity.

\section{Results and discussion}

So, the formation and development of labor potential in the country should be based on the "three pillars" (indicators):

- The ratio of employed to the total working population;

- The ratio of education to those employed in the respective fields of activity;

- The ratio of managers and workers in the country.

Thus, in terms of ensuring and developing human resources in the conditions of an innovative economy, it is necessary to focus on two key indicators: "coefficient of efficiency of use of labor potential in the country" and "coefficient of efficiency of using innovative potential in the country", as well as to increase the interest of the personnel involved in innovative processes (the introduction of the indicator "innovative activity" in the stimulating part of wages).

We are moving from global issues to narrowly focused ones. The modern concept of labor activity presupposes to consider the personnel of industrial enterprises as one of the most valuable resources of the production sector, which means that increasing their competitiveness is possible only through the formation and development of a competent level of workers corresponding to cyclical environmental trends. The formation of complex integrated associations leads to a more efficient use of human potential in order to maximize commercial results.

The basis of the innovation processes of the personnel management system is to ensure the survival of industrial enterprises through higher rates of formation and development of their human resources in comparison with changes in the external environment. Therefore, the main task is to adapt the industrial enterprise not to the very changes in the environment (they always occur), but to the speed of these changes.

In modern conditions of the functioning of production companies, the tasks of streamlining the personnel management system are becoming the most priority area of economic activity on the basis of innovatively oriented methods. Each business entity is interested in their decision. Meanwhile, the intensification of labor activity is characterized by more demanding approaches to the managerial environment in order to increase the innovative potential of industrial enterprises, given the harsh conditions of increasing 
competition. This is, first of all, the uncertainties and risks in the activities of each enterprise and its employees, as well as the transitional processes with which they are covered. All this gives particular importance to the personnel management system based on the improvement of innovative processes.

The dynamic development of integration processes in the economic activity of industrial enterprises, based on diversified approaches, is accompanied by the need to develop organizational management structures, transform rigid hierarchical structures into flexible ones; adaptive, consisting of units, each of which is engaged in a certain type of production activity and through it organically fits into the design of the entire system and the concept of business activity of its employees. The transition to flexible, non-bureaucratic structures puts forward in the first-place factors that have a direct impact on the economic activity of an industrial enterprise. In this regard, a modern technology for human resource management should be designed based on the principles of developing the competence level of workers in order to optimize the production sphere.

Since the basis of the concept of the personnel management system is human potential, the innovative development of an industrial enterprise is a direct activity not only of managers of personnel management services, but also of heads of all departments, as well as all employees directly related to the formation and development of innovative potential. The subject of labor in this case is a person as a source and carrier of information, quality; reliability; the volume and speed of which is determined by a set of real competencies.

The essence of the design of innovative transformations in the personnel management system is based on a certain methodology for changing the personnel of an industrial enterprise in the context of improving labor activity. The algorithm for designing innovative transformations should be governed by the goals of the personnel management system and the goals of the industrial enterprise as a whole. The result of the design is a comprehensive assessment of the innovative potential of the workforce.

It follows that the goal of the personnel management system by improving innovative processes is to ensure the development of the labor potential of an industrial enterprise based on modern approaches to personnel work. She focuses on the fundamental ideas of the formation, development and implementation of labor potential, which make up the concept of a personnel management system. The basis of this concept should be the participation of personnel in the connecting processes that ensure consistency between the general and special management functions, i.e. between all types of work in an industrial enterprise as a single organism. Among such processes, innovation development is a priority.

The success of enterprises is provided by employees engaged in the innovation process. Therefore, the modern concept of management involves the separation from a large number of functional areas of management activity precisely that which carries innovative potential. From this it follows the feasibility of calculating the innovativeness of personnel according to the proposed formula.

$$
\mathrm{I}_{\mathrm{p}}=\mathrm{S}_{\mathrm{p}} * \mathrm{Q}
$$

where:

$I_{p}$ - innovativeness of the personnel of the industrial enterprise (the contribution of employees engaged in innovative processes in the volume of production of the company);

$\mathrm{S}_{\mathrm{p}}$ - the share of innovative personnel in the total number of industrial enterprises;

$\mathrm{Q}$ - the volume of production in value or in kind.

$$
\mathrm{S}_{\mathrm{p}}=\mathrm{N}_{\mathrm{i}} / \mathrm{N}_{\mathrm{p}}
$$


where:

$\mathrm{N}_{\mathrm{i}}$ - the number of personnel directly related to the production processes of an innovative nature;

$\mathrm{N}_{\mathrm{p}}$ - the average number of personnel in the industrial enterprise.

Using this method, we can calculate the coefficient of innovation activity and determine for ourselves what level of staff involvement in the innovation process exists in a production company. This approach is very important in modern conditions because it shows us the real degree of staff interest in innovative technologies. It is very important to understand the meaning of the formula. In fact, we find the proportion of employees who are engaged in the innovation process. But what about the innovation process? For example, if an employee works on modern production equipment, they will be considered to be innovatively active employees. In other words, it is not necessarily about creative work. Any employee who is involved in innovation (even indirectly) determines this indicator. Based on this approach, we can conduct statistical analysis, identifying the dynamics of the development of this indicator.

Currently, in the face of increasing competition, many leaders of industrial enterprises underestimate the importance of personnel management methods that are characteristic of modern innovative management and are actively used in developed countries to effectively manage economic entities and increase the profitability of their production.

Changes in the principles of the personnel management system of industrial enterprises should be directed, first of all, to the implementation of the policy of innovative development of labor potential, acquiring decisive importance in modern conditions. Based on this, we propose to formulate a new classification of the innovative process of development of the production and labor sectors (Fig. 1).

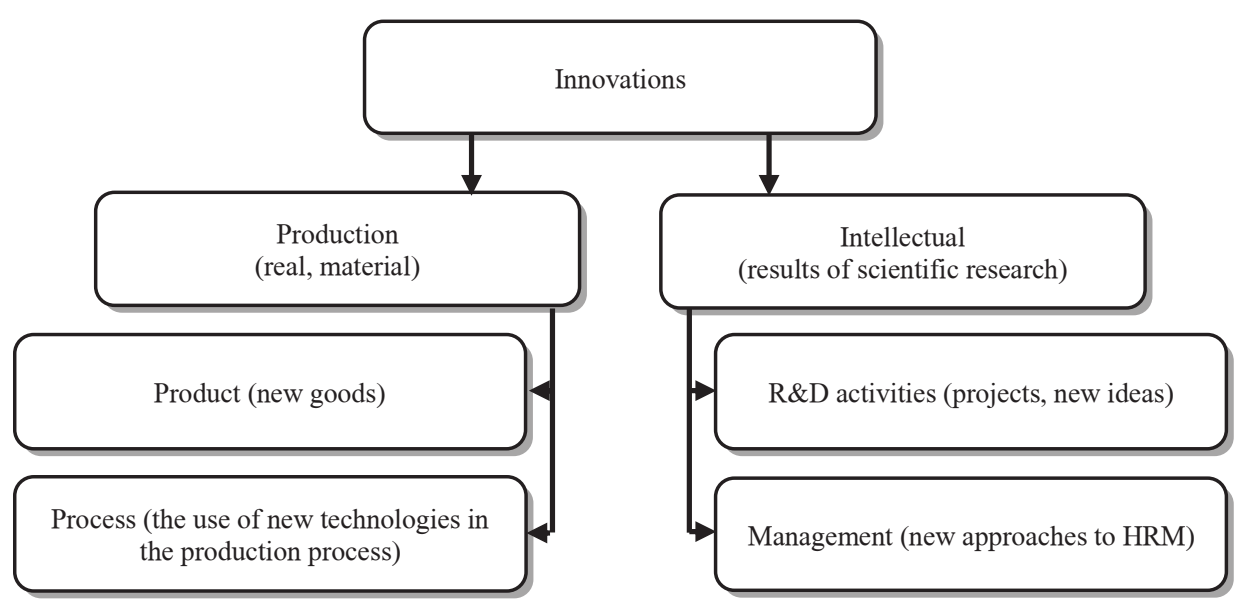

Fig. 1. Modern classification of innovation

In the context of the development of integration processes (industrial holdings and industrial groups), the involvement of employees in management activities is due to the innovation policy in the personnel management system. Such activities should be aimed at effectively expanding the interaction of the personnel management system and the production sector in order to achieve common goals oriented towards the use of innovative methods. This directly encourages staff to develop potential abilities, more intensive and productive work, and a creative attitude to work. The creative approach, in turn, determines an increase in the independence and responsibility of employees for the work performed, active participation in managerial decisions, and a direct interest in the results of their work. 
Therefore, the personnel management system at industrial enterprises should be aimed at improving educational levels; qualifications and culture of workers in all categories; providing a wide circle of workers with conditions for expanding professional knowledge; continuous improvement of their skills; increase self-expression; growth of competency level, as well as the development of innovative and corporate culture. Such an approach will allow industrial enterprises to carry out personnel activities in labor activities on a more promising and strategically important basis.

It becomes very important to identify key factors in ensuring innovative priorities in human resource management. Each employee represents a certain labor potential, which is characterized by quantitative and qualitative characteristics. Quantitative characteristics will include such as labor productivity. But quantitative characteristics do not give an accurate idea of the possibility of implementing innovations. They can only serve as a consequence and result of innovation. But the quality characteristics of an employee are a fundamental criterion in the transition to innovative technologies. Because they include the level of education, work experience, and the ability to change in the world around you. This is very relevant at the moment, especially if we are talking about lean manufacturing as a leading concept in operational management. Below is a matrix that shows a list of innovation factors with a breakdown of tasks in the context of human resource management. In other words, each factor determines a certain task for working with personnel, i.e. what the employee should do to ensure this factor and ultimately implement innovation. (table 3).

Table 3. Matrix of factors for using innovative processes by labor resources

\begin{tabular}{|l|l|}
\hline \multicolumn{1}{|c|}{ Factor } & \multicolumn{1}{c|}{ Task } \\
\hline Activation of innovation & $\begin{array}{l}\text { Application of modern technologies to involve } \\
\text { employees in the innovation process }\end{array}$ \\
\hline Ensuring the effectiveness & $\begin{array}{l}\text { Establishment of the innovation indicators influencing } \\
\text { the efficiency }\end{array}$ \\
\hline Stability of personnel & $\begin{array}{l}\text { Increase in interest by innovative technologies with } \\
\text { able to self-realization }\end{array}$ \\
\hline Guarantee of development & $\begin{array}{l}\text { Set up innovation as a key condition for company } \\
\text { growth }\end{array}$ \\
\hline Continuous improvement & Optimal use of all resources with maximum efficiency \\
\hline
\end{tabular}

The presented matrix provides an opportunity to look at the use of human resources in a more modern way since innovative technologies can only be implemented at the expense of people. From table 3, we can see that for all the variety of factors, the innovation context remains the key. Each factor can add value to the company if the tasks for its provision are clearly performed. For example, the activation of innovations is possible only through the involvement of staff. The effectiveness of the company as a whole is possible due to innovation performance. The stabilization of the personnel is possible due to the increase of interest in innovation. The guarantee of development is possible only by changing the priority in direction of innovation. Continuous improvement is only possible through the optimization of all processes (of course, with the use of innovations).

\section{Conclusion}

1. The effective development of the personnel management system should be based on innovatively-oriented methods of economic activity of industrial enterprises. The competencies of employees in all categories of personnel are considered as the basis for improving innovation processes. These competencies are a combination of professional 
knowledge and work skills that carry innovative ideas and abilities necessary for the implementation of production activities.

2. In order to assess the degree of innovative development of an industrial enterprise, it is necessary to use the personnel innovation indicator as one of the main criteria for the comprehensive characteristics of modern production. The level of development of the innovative potential of an industrial enterprise is determined precisely by the human factor.

3. To implement radical measures to improve the personnel management system, industrial enterprises should be oriented both to the production sector and to human resources. The effective interaction of these elements, savvy in innovation priority, will allow industrial enterprises to develop dynamically, adequately and flexibly responding to cyclical changes in scientific and technological progress and the environment as a whole.

4. The industrial company's focus on an innovative way of development creates new challenges for the competitive market. The use of modern approaches to human resource management creates a huge opportunity to increase interest in innovative technologies among employees. The main task of the management of industrial companies is to learn how to efficiently use the labor potential for the development of innovations.

\section{References}

1. J. West, M. Bogers, Journ. of Prod. Innov. Manag., 31, 814 (2014)

2. M. Bogers, J. West, Creat.\& Innov. Manag., 21, 61 (2012)

3. V. Van de Vrande, J.P.J. de Jong, W. Vanhaverbeke, M. de Rochemont, Open Techn., 29, 423 (2009)

4. D. Chiaroni, V. Chiesa, F. Frattini, R\&D Manag., 40, 222 (2010)

5. E. Almirall, R. Casadessus-Masanell, Acad. of Manag. Rev., 35, 27 (2010)

6. O. Shenkar, How Smart Companies Use Imitation to Gain a Strategic Edge, Harvard Business Review Press (2010)

7. H.W. Chesbrough, E.L. Chen, Journ. of Innov.Manag., 3, 21 (2015)

8. G.P. Pisano, Harv.Bus. Rev., 6, 44 (2015)

9. A. Winter, V. Govindarajan, Harv. Bus. Rev., 7, 80 (2015)

10. R.V. Costa, A.P. Ramos, Inter. Journ. of Bus. Sc.\& Appl. Manag., 10(1), 15 (2015)

11. M. Rhaieiu, Journ. of Inter. Bus.\& Econ., 12(3), 102 (2012)

12. H. Forsman, U. Annala, Inter.Journ. of Tech. Manag., 56, 154 (2011)

13. D. Schiliro, Journ. of Adv. Res. in Manag., II (2), 89 (2011) 